\title{
The Factors Affecting Women's Decision About Unplanned Pregnancy: A Hierarchical Modeling Strategy
}

\author{
Neda Nikkhesal ${ }^{\circledR}$, Roghaiyeh Nourizadeh $^{1}$, Saeed Dastgiri $^{2}$, Esmat Mehrabi $^{{ }^{*}}{ }^{(\mathbb{D}}$
}

\begin{abstract}
Objectives: Many women experience unplanned pregnancies in their life and have to make a critical decision whether to abort or continue with the pregnancy. The present study aimed to assess the factors affecting the decision about unplanned pregnancies. Materials and Methods: The present prospective study was conducted on 230 women with unplanned pregnancy who were selected through sequential sampling, including 80 women who had decided to abort and 150 who had decided to continue with their unplanned pregnancy, and referred to health complexes and centers, and obstetrics and midwifery offices in Tabriz, Iran, in 2017. Data were collected through perceived threats, support, and beliefs and values questionnaires and analyzed using the $\mathrm{t}$-test and the logistic regression with a hierarchical modeling strategy.

Results: According to the results, the mean scores of perceived threats (40.02 \pm 5.5$)$, perceived support (23.09 \pm 2.8$)$, and beliefs and values $(18.12 \pm 3.2)$ were significantly higher in the abortion group compared to the continuation group (19 $\pm 3.3,21.04 \pm 3.05$ and $11.2 \pm 4.3 ; P<0.001)$. The results of the hierarchical modeling strategy showed that the perceived threats of the continuation of pregnancy had the greatest predictive power over the decision to abort $(\beta=1.12 ; 95 \% \mathrm{CI}$ : $1.08-1.17 ; P<0.001)$.

Conclusions: The results of this study showed that women's decision about the outcome of unplanned pregnancy is potentially affected by three groups of reasons, including perceived threats, support, and beliefs and values. Indeed, understanding these factors provides a broad picture of the situations affecting women's decision-making. The findings of this study suggest the need for planning and implementing counseling interventions based on the abovementioned factors, especially identifying perceived threats and providing appropriate strategies to remove these threats in women who have to make such critical decision in their life.

Keywords: Unplanned pregnancy, Abortion, Decision making
\end{abstract}

\section{Introduction}

Over the course of reproductive years, most women across the world, experience an unplanned pregnancy and the challenges of decision making about this pregnancy. Due to the changes in people's lifestyles, such as urbanization and socioeconomic developments, women are often inclined to have fewer children and therefore make great efforts to avoid unwanted pregnancies in their reproductive ages. Nevertheless, given the fact that no method of contraception is $100 \%$ successful in preventing unplanned pregnancies, even women who use contraceptive methods are likely to experience unplanned pregnancies and face the challenge of decision making about it (1-4).

Unplanned pregnancies faced by women are divided into two categories: unwanted pregnancies and mistimed pregnancies $(5,6)$. It is reported that $40 \%$ of pregnancies in the world are unplanned, from which $50 \%$ are ended with induced abortion, $13 \%$ are ended with spontaneous abortion, and $37 \%$ are continued (5). It is worth noting that almost $25 \%$ of pregnancies around the world end with induced abortion during 2010-2014 (7). A meta-analysis conducted in 2012 in Iran reported the rate of unplanned pregnancies as 27.94\% (8-10). Almost 22000000 unsafe induced abortions are performed in the world every year (11), and 4 out of every 10 women who resort to unsafe abortion methods suffer from abortion-induced complications $(12,13)$. Deaths caused by unsafe abortions are reported as 520 cases in African countries, 220 cases in developing countries, and 30 cases in developed countries per every 100000 abortions (11). In Iran, 1 out of every 4 women experiences induced abortion in her reproductive period (14). Because of their illegal nature in some countries, induced abortions are largely unsafe, unless a disease or severe and fatal abnormality is detected in the fetus, or the mother's life is threatened, in which case, the coroner issues a permission for medical abortion. Under all other conditions, women are forced to resort to unsafe and clandestine methods for discontinuing their pregnancy, which may entail serious and harmful consequences for them $(9,15)$. In addition to endangering the women's own health and life, whole families and the community are also affected. Generally, induced abortion

\footnotetext{
Received 13 February 2018, Accepted 20 March 2018, Available online 9 April 2018
}

${ }^{1}$ Department of Midwifery, Faculty of Nursing and Midwifery, Tabriz University of Medical Sciences, Tabriz, Iran. ${ }^{2}$ Health Services Management Research Center, Tabriz University of Medical Sciences, Tabriz, Iran.

*Corresponding Author: Esmat Mehrabi, Tel: +989144142991, Email: b.mehrabi62@gmail.com, 
imposes huge direct and indirect burden on the family and the health system in every country and leaves the fetus incapable of defending himself or choosing his fate $(11,16)$.

Many factors are involved in deciding about the outcome of unplanned pregnancies, including the spouse and family views, thinking about the unborn fetus, moral beliefs and values, rules and policies, socioeconomic factors, religion, beliefs, feelings and many other unknown factors (17). One problem is that the decision to abort is not only a great source of stress for the mother and her family, the continuation of the unplanned pregnancy is also a source of stress and challenge for the mother, the family, and the health system. Although pregnancy promises the birth of new life and is happy news, it is perceived as a threat in these families and makes women face a big challenge due to the loss of their personal peace and family stability or the loss of career and academic opportunities and the violation of their value and belief system (18). Mothers' non-acceptance of and dissatisfaction with their pregnancy leads to psychological and emotional problems in women and stress in men, and due to their unpleasant emotions about this incident, women may develop nervous symptoms such as aggression, sleep disturbances and nightmares, physical weakness, low birth weight, and prenatal fatigue and depression, which are the most common consequences of continued unplanned pregnancies $(19,20)$. Mothers' failure to come to terms with an unplanned pregnancy leads to diminished maternal responsibilities, unhealthy prenatal behaviors such as a disregard for diet and not presenting on time for prenatal care visits, which result in increased perinatal mortality rates (19). Compared to children born from wanted and planned pregnancies, the children born from unplanned pregnancies develop behavioral problems and have a poorer family performance, and ultimately, the lack of attention to the unwanted child, the rejection of the child and his poor upbringing harm the community's health. This group of women and their families thus require greater family, organizational, and social support (19).

The existence of a political environment with regard to abortion in most the countries, accompanied by the economic recession may affect women's decision to abort or continue with the unplanned pregnancy; this necessitates a new investigation on the factors affecting women's decision-making. It is worth noting that most studies conducted on unplanned pregnancies have not addressed the related predictive factors affecting the decision made by women and their families when confronting with an unplanned pregnancy. Although the most recent researches about women's reasons for abortion or continuance of the unplanned pregnancy have focused on developed countries and prior researches included developed and developing countries, performed many years ago, the reasons why women decide to abort or continue with the unplanned pregnancy may have changed $(21,22)$.

This paper attempted to fill this gap in the literature using a comprehensive and specialized questionnaire and evaluation of factors affecting women's decision making when confronting with unplanned pregnancy. Given the prevalence of unplanned pregnancies, the legal restrictions on abortion in most countries and the gap in literature about this issue, the present study was designed and conducted to identify the factors affecting the decision to abort or continue with an unplanned pregnancy, because providing early counseling services and interventions to these women and their families so as to prevent future problems in the families and the larger community can be helpful. Therefor the present study aimed to explore the factors causing to decide about the unplanned pregnancy.

\section{Materials and Methods}

The present prospective study was conducted, through sequential sampling, from June to September 2017, on 80 women with the decision to terminate their unplanned pregnancy and 150 women with the decision to continue. The researcher identified eligible women by visiting health centers (to find subjects deciding to continue with their pregnancy) and midwifery and gynecology offices and clinics (to find subjects deciding to abort), and informed them on the study objectives and methods and obtained written consents from those willing to take part in this research. Married women aged 15-49 with an unplanned pregnancy entered the study. The exclusion criteria consisted of known maternal or fetal physical diseases which were subject to induced abortion, known maternal psychological disorders, and abortions that had legal permission due to fetal abnormalities.

Data were collected using a demographic questionnaire and specific tools for assessing perceived threats, support, and values and beliefs in women faced unplanned pregnancy. The perceived threats questionnaire contained 31 items in 6 dimensions, including fear of fetal abnormalities and fear of deviation from social norms (7 items), fear of hardship and the exacerbation of life instability (6 items), fear of parental responsibility and commitments (6 items), abortion phobia and aversion (6 items), conflicting roles and social deprivations (3 items), and fear of negative physical-emotional outcomes (5 items). The maximum score obtainable for the perceived threats of continuing pregnancy was 81 and that for the perceived threats of abortion was 12 . Higher scores in each domain indicated greater perceived threats. The Cronbach $\alpha$ coefficient for this questionnaire was 0.88 and its intra-class correlation coefficient with a 2-week interval was 0.89 , indicating the high reliability of the tool. The perceived support questionnaire for unplanned pregnancies contained 18 items in 4 dimensions, including instrumental support (4 items), family cooperation (3 items), information support and advices (5 items), and 
other's ideas and feelings (6 items). The perceived support questionnaire had no cut-off point in this study and only the total score of perceived support for predicting the decision to abort or continue with an unplanned pregnancy was important to the researchers. The Cronbach $\alpha$ coefficient for this questionnaire was 0.79 and the intra-class correlation coefficient with a two-week interval was 0.86 , indicating the high reliability of the tool. The abortionrelated perceived beliefs and values scale contained 12 items in 2 domains, including abortion-moderating beliefs and values ( 6 items) and abortion-facilitating beliefs and values (6 items), and the responses included high (3 points), medium (2 points), low (1 point), and not at all (0 point) options. Higher scores in each domain indicated more abortion-facilitating or moderating beliefs and values. The Cronbach a coefficient for this questionnaire was 0.8 and its intra-class correlation coefficient with a 2 -week interval was 0.95 , indicating the high reliability of the tool (23). Data were collected through interviews and questionnaires and then analyzed in SPSS version 24.0 using the $t$ test and the logistic regression analyses.

\section{Results}

The mean age of the participating women with unplanned pregnancy was $31.1 \pm 6.75$ and the mean age of their spouses was $35.32 \pm 4.4$. About two-thirds of the women and their spouses with a diploma or below level of education had decided in favor of abortion. A total of $78 \%$ of those who had decided to abort had 2 or more children. The gestational age of the majority $(80 \%)$ of the women who had decided to abort was equal or less than 5 weeks. Most participants (73\%) had no history of induced abortion. Almost half (48\%) of those deciding to abort did not have sufficient family income. A total of $63 \%$ of those who had decided to abort had unwanted pregnancy and $65 \%$ of those who had decided to continue with their unplanned pregnancy had mistimed pregnancy (Table 1).

In the abortion group, the mean scores were 40.02 \pm 5.5 for perceived threats, $23.09 \pm 2.8$ for perceived support, and $18.12 \pm 3.2$ for beliefs and values, which were significantly higher $(P<0.001)$ than the scores obtained in the continuation group $(19 \pm 3.3 ; 21.04 \pm 3.05 ; 11.2 \pm 4.3)$. The mean scores of the fear of fetal abnormalities and fear of deviation from social norms, fear of hardship and the exacerbation of life instability, fear of parental responsibility and commitments, conflicting roles and social deprivations, and fear of negative physicalemotional outcomes were significantly higher in the abortion group compared to the continuation group; however, the mean score of abortion phobia and aversion was significantly higher in the continuation group compared to the abortion group. The mean scores of perceived support in the dimensions of instrumental and information support and advices were significantly higher in the abortion group compared to the continuation group. The mean score in the dimension of other's ideas and feelings was significantly higher in the continuation group compared to the abortion group $(P<0.038)$. The mean score of abortion-moderating beliefs and values was significantly lower in the abortion group compared to the continuation group, while the mean score of abortionfacilitating beliefs and values was significantly higher in the abortion group compared to the continuation group (All $P<0.05$; Table 2).

According to the results of the hierarchical modeling strategy using a simple logistic regression (unadjusted OR's) for assessing the relationship between demographic variables and the women's decision with regard to their unplanned pregnancy, variables of age, spouse's education, gestational age, number of children, and fetal gender were significantly correlated with the abortion or continuation decision in unplanned pregnancy (All $P<0.05$ ). Women who were younger than 26 had a $70 \%$ higher odds ratio to decide to abort compared with the women older than 37. The decision to abort was three times more frequent in the women whose spouses were at an education level less than diploma compared to those with spouses who had university education. The decision to abort was nine times more frequent in the women with gestational ages $\leq 5$ weeks compared to those with gestational ages $>5$ weeks. The women with 2 or more children were $60 \%$ more likely to decide to abort compared to the women with one child. The discussed demographic variables met the criteria for a multivariate regression analysis and all the variables were statistically significant (All $P<0.05$; Table 3 ).

According to the results of the hierarchical modeling strategy using the simple logistic regression (unadjusted OR's) for assessing the relationship between perceived threats, perceived support, and beliefs and values and the women's decision about unplanned pregnancies, all the three variables were found to have significant relationships with the abortion decision (All $P<0.05$ ). The odds of deciding to abort in women with unplanned pregnancies increased significantly by $20 \%$ in the perceived threats domain, as the fear of hardship and the exacerbation of instability, fear of fetal abnormalities and fear of deviation from social norms, fear of parental responsibility and commitments, and conflicting roles and social deprivations increased. In the perceived support domain, it increased by $40 \%$ and $12 \%$ as instrumental support and information support and advices increased, and in the beliefs and values domain, it increased by $20 \%$ as perceived abortion-facilitating beliefs increased (All $P<0.05$ ). These variables met the criteria for the multivariate regression analysis, and the odds of deciding to abort increased significantly by $25 \%$ in the perceived threats domain as conflicting roles and social deprivations increased and then by $30 \%$ in the perceived support domain as the women's perceived family cooperation increased. In the beliefs domain, perceived abortion-moderating beliefs significantly decreased the odds of deciding to abort one time more (All $P<0.05$; Table 3). 
Table 1. Demographic Characteristics of Study Subjects

\begin{tabular}{|c|c|c|c|}
\hline Characteristics & $\begin{array}{c}\text { Subjects }(n=230) \\
\text { No. }(\%)\end{array}$ & $\begin{array}{c}\text { Continuation Group }(n=150) \\
\text { No. (\%) }\end{array}$ & $\begin{array}{c}\text { Abortion Group }(n=80) \\
\text { No. (\%) }\end{array}$ \\
\hline \multicolumn{4}{|l|}{ Age (y) } \\
\hline $21-30$ & $19(9)$ & $12(8)$ & $7(9)$ \\
\hline $31-40$ & $211(91)$ & $138(92)$ & $73(91)$ \\
\hline \multicolumn{4}{|l|}{ Husband's age (y) } \\
\hline $21-30$ & $1(1)$ & $0(0)$ & $1(1)$ \\
\hline $31-40$ & 229 (99) & $150(100)$ & $79(99)$ \\
\hline \multicolumn{4}{|l|}{ Job } \\
\hline Housewife & $192(83)$ & $129(85)$ & $63(78)$ \\
\hline Employed & $38(17)$ & $19(15)$ & $17(22)$ \\
\hline \multicolumn{4}{|l|}{ Husband's job } \\
\hline Employee & $37(16)$ & $26(17)$ & $11(13)$ \\
\hline Self-employed & $193(84)$ & $124(83)$ & $69(87)$ \\
\hline \multicolumn{4}{|l|}{ Education } \\
\hline Diploma and lower & $185(80)$ & $124(83)$ & $61(80)$ \\
\hline Academic & $45(20)$ & $26(17)$ & $19(20)$ \\
\hline \multicolumn{4}{|l|}{ Husband's education } \\
\hline Illiterate & $178(77)$ & $117(78)$ & $61(77)$ \\
\hline Academic & $52(23)$ & $33(22)$ & $19(23)$ \\
\hline \multicolumn{4}{|l|}{ Income level } \\
\hline Inadequate & $92(40)$ & $53(35)$ & $39(48)$ \\
\hline Somewhat enough & $99(43)$ & $67(45)$ & $32(41)$ \\
\hline Enough & $39(17)$ & $30(20)$ & $9(11)$ \\
\hline \multicolumn{4}{|l|}{ Number of children } \\
\hline 0 & $19(8)$ & $9(6)$ & $10(12)$ \\
\hline 1 & $79(34)$ & $70(46)$ & $9(11)$ \\
\hline 2 & $92(40)$ & $56(39)$ & $36(46)$ \\
\hline $3+$ & $40(18)$ & $15(9)$ & $25(32)$ \\
\hline \multicolumn{4}{|l|}{ Gestational age (wk) } \\
\hline$\geq 5$ & $96(41)$ & $46(30)$ & $50(62)$ \\
\hline $6-8$ & $106(46)$ & $78(52)$ & $28(35)$ \\
\hline$<9$ & $28(13)$ & $26(18)$ & $2(3)$ \\
\hline \multicolumn{4}{|c|}{ Previous induced abortion } \\
\hline Yes & $45(20)$ & $23(15)$ & $22(27)$ \\
\hline No & $185(80)$ & $127(85)$ & $58(73)$ \\
\hline \multicolumn{4}{|c|}{ Type of unplanned pregnancy } \\
\hline Unwanted & $103(45)$ & $52(35)$ & $51(63)$ \\
\hline Mistimed & $127(55)$ & $98(65)$ & $29(37)$ \\
\hline \multicolumn{4}{|c|}{ The sex of aborted fetus } \\
\hline Female & $1(1)$ & $1(1)$ & $0(0)$ \\
\hline Unclear & 229 (99) & 149 (99) & $80(100)$ \\
\hline \multicolumn{4}{|l|}{ The sex you desire } \\
\hline Female & $16(6)$ & $13(8)$ & $3(3)$ \\
\hline Male & $24(11)$ & $24(15)$ & $2(2)$ \\
\hline It does not matter & $190(83)$ & $115(76)$ & $75(95)$ \\
\hline
\end{tabular}

\section{Discussion}

This study was conducted to investigate the factors affecting the women's decision about an unplanned pregnancy. The results of the hierarchical modeling strategy showed the significant effects of variables such as mother's age, spouse's education, number of children, gestational age, and perceived threats, support, and beliefs and values on women's decision in unplanned pregnancies (i.e. abortion or continuation of pregnancy). Among the related factors, perceived threats related to conflicting roles and social deprivations and fear of fetal abnormalities, perceived support related to family cooperation, and information support and advices were the most effective factors in the women's decision to abort their unplanned pregnancy. In addition, abortion-moderating beliefs were the most effective factors in the women's decision for the continuation of their pregnancy.

In the present study, financial pressures and fear of 
Table 2. Comparison of Mean \pm SD of Perceived Threats, Supports, and Beliefs and Values Among Women Faced Unplanned Pregnancy in 2 Groups (With Decision to Abort or Continue With Pregnancy)

\begin{tabular}{llcr}
\hline & Perceived Beliefs and Values & Perceived Support & Perceived Threats \\
\hline Groups, Mean \pm SD & & & \\
Abortion group & $18.12 \pm 3.2$ & $23.09 \pm 2.80$ & $40.02 \pm 5.50$ \\
Continuation group & $11.20 \pm 4.3$ & $21.04 \pm 3.05$ & $19.00 \pm 3.30$ \\
\hline
\end{tabular}

Table 3. Results of Logistic Regression for Unadjusted and Adjusted Odds Ratios (ORs) for Variables Related to Decision on Abortion

\begin{tabular}{|c|c|c|c|c|c|c|c|c|}
\hline \multirow{2}{*}{ Variables } & \multicolumn{4}{|c|}{ Adjusted } & \multicolumn{4}{|c|}{ Unadjusted } \\
\hline & $P$ value & Upper & Lower & OR & $P$ value & Upper & Lower & OR \\
\hline Perceived threats & $<0.001$ & 1.10 & 1.05 & 1.08 & $<0.001$ & 1.17 & 1.08 & 1.12 \\
\hline Fear of responsibility and parenting commitments & 0.11 & 1.29 & 0.97 & 1.12 & 0.005 & 0.97 & 0.86 & 0.80 \\
\hline Fear of anomalies and violation of the norm & 0.32 & 1.07 & 0.80 & 0.93 & 0.001 & 0.93 & 0.83 & 0.80 \\
\hline Fear of hardship and Instability & 0.60 & 1.13 & 0.80 & 0.95 & $<0.001$ & 0.93 & 0.81 & 0.82 \\
\hline Conflicting roles and social deprivation & 0.04 & 0.99 & 0.57 & 0.75 & 0.004 & 0.94 & 0.72 & 0.82 \\
\hline Fear of negative physical-emotional consequences & 0.80 & 1.27 & 0.73 & 0.96 & $<0.001$ & 0.87 & 0.71 & 0.79 \\
\hline Abortion phobia and aversion & 0.47 & 1.11 & 0.79 & 0.93 & 0.01 & 1.20 & 1.02 & 1.1 \\
\hline Perceived support & 0.05 & 1.07 & 1.00 & 1.03 & 0.05 & 1.15 & 0.91 & 0.98 \\
\hline Toolkit support & 0.77 & 1.03 & 0.58 & 0.77 & $<0.001$ & 0.75 & 0.54 & 0.62 \\
\hline Collaboration on tasks & 0.05 & 1.0 & 0.47 & 0.69 & 0.6 & 1.16 & 0.90 & 1.02 \\
\hline Information support and advices & 0.35 & 1.11 & 0.74 & 0.90 & 0.007 & 0.96 & 0.80 & 0.88 \\
\hline Comments and feelings of others & 0.53 & 1.28 & 0.88 & 1.06 & 0.5 & 1.09 & 0.95 & 1.02 \\
\hline Perceived values and beliefs & 0.03 & 0.99 & 0.78 & 0.87 & 0.03 & 1.04 & 0.93 & 0.9 \\
\hline Moderating believes and values & 0.001 & 1.54 & 1.11 & 1.31 & $<0.001$ & 1.33 & 1.15 & 1.2 \\
\hline Facilitating believes and values & 0.13 & 1.04 & 0.73 & 0.87 & $<0.001$ & 0.86 & 0.75 & 0.81 \\
\hline Age (y) & 0.006 & - & - & - & 0.011 & - & - & - \\
\hline $26 \leq$ & 0.40 & 3.43 & 0.04 & 0.40 & 0.004 & 0.69 & 0.14 & 0.31 \\
\hline $27-32$ & 0.38 & 2.40 & 0.10 & 0.49 & 0.08 & 1.09 & 0.25 & 0.52 \\
\hline $33-36$ & 0.001 & 0.29 & 0.01 & 0.05 & 0.005 & 0.70 & 0.13 & 0.30 \\
\hline $37+$ & Referent & - & - & - & - & - & - & - \\
\hline Husband's education & $<0.001$ & - & - & - & 0.001 & - & - & - \\
\hline Illiterate & 0.30 & 4.32 & 0.009 & 0.20 & 0.29 & 10.59 & 1.13 & 3.46 \\
\hline Elementary/guidance & $<0.001$ & 0.06 & 0.00 & 0.005 & 0.30 & 0.92 & 0.20 & 0.43 \\
\hline High school/diploma & 0.02 & 0.77 & 0.25 & 0.13 & 0.66 & 2.47 & 0.56 & 1.17 \\
\hline Academic & Referent & - & - & - & - & - & - & - \\
\hline Gestational age (wk) & $<0.001$ & - & - & - & $<0.001$ & - & - & - \\
\hline$\leq 5$ & 0.001 & 246.01 & 4.52 & 33.36 & 0.001 & 32.02 & $2 / 56$ & 9.05 \\
\hline 6 & 0.005 & 149.32 & 2.45 & 19.14 & 0.007 & 22.41 & 1.63 & 6.06 \\
\hline $7-8$ & 0.8 & 8.90 & 0.07 & 0.80 & 0.70 & 3.57 & 0.15 & 0.74 \\
\hline $9+$ & Referent & - & - & - & - & - & - & - \\
\hline Number of children & $<0.001$ & - & - & - & $<0.001$ & - & - & - \\
\hline 0 & 0.3 & 2.01 & 0.22 & 0.20 & 0.47 & 2.01 & 0.22 & 0.66 \\
\hline 1 & $<0.001$ & 0.21 & 0.03 & 0.00 & $<0.001$ & 0.21 & 0.03 & 0.08 \\
\hline 2 & 0.024 & 0.82 & 0.18 & 0.13 & 0.015 & 0.82 & 0.18 & 0.38 \\
\hline $3+$ & Referent & - & - & - & - & - & - & - \\
\hline The sex you desire & 0.004 & - & - & - & 0.01 & - & - & - \\
\hline Female & 0.93 & 8.84 & 0.13 & 1.08 & 0.10 & 1.25 & 0.09 & 0.34 \\
\hline Male & 0.001 & 0.17 & 0.001 & 0.014 & 0.008 & 0.59 & 0.03 & 0.13 \\
\hline It does not matter & Referent & - & - & - & - & - & - & - \\
\hline
\end{tabular}


continuing marital life as part of the domain of 'fear of hardship and the exacerbation of instability', the loss of social status and role dysfunction as part of the construct 'conflicting roles and social deprivation' and increased number of children as part of the domain of 'fear of deviation from social norms' were among the factors predicting the decision to abort, and they increased the frequency of this decision by $10 \%$ to $25 \%$. These results supported the results obtained in similar studies, which proposed the loss of social status following pregnancy, conflicting roles, increased number of children, concern about the continuation of marital life and financial pressures as reasons for abortion (24-27). Frederico et al in their qualitative study reported that women's lack of autonomy to make their own decisions regarding the termination of the pregnancy was an important factor affecting their decisions (28). Their findings were similar to the results of the present study in domain of perceived threats and also perceived supports from the family.

In the present study, fear of financial support of the unwanted child, risking the welfare of other children in the family, and the ability to perform maternal responsibilities as part of the construct 'fear of parental responsibility and commitments' affected the decision to abort. In a study conducted in the United States by Hoogen, women's interpretation of 'being a good mother' played a major role in deciding to abort, to such an extent that some women interpreted the discontinuation of their pregnancy as part of 'being a good mother', since they had a family-oriented rather than fetal-oriented approach to motherhood and considered the welfare of the other family members as well, including the unwanted child's after birth, and so, to them, a good mother was responsible for the welfare of the entire family (29). Moreover, in a study by Wilson and McQuiston, securing a good life for one's children and ensuring a happy family life were among the reasons Mexican women considered in planning their pregnancies (30).

In line with our study results, also in a study by Mohammadi et al, women's mental picture of their body (concern about skin pigmentations and pregnancyrelated obesity) and fear of negative emotional outcomes (appearing older) as consequences of continuation of unplanned pregnancy were among the factors that gave way to abortion in women (27).

Consistent with the results obtained for the study of Bankole et al, which reported fear of maternal health risks as the main reason for choosing abortion, the present study also showed fear of the unfavorable effect of maternal higher age on pregnancy, possible adverse effects of medications used or exposure to radiation during the pregnancy on the fetus (the 'fear of abnormalities' dimension of perceived threats), and so on could affect the decision to abort the unwanted pregnancy (21).

In the present study, the role of others' feelings and ideas was more linked to the continuation of pregnancy rather than abortion. Several studies have demonstrated the major effect of the reactions of the spouse and relatives on the outcome of a pregnancy, especially an unplanned pregnancy. For example, in one study, Bayrami et al reported that the attitudes of the spouse, mother, and mother-in-law played an effective role in the acceptance and continuation of pregnancy in women in the critical stage of choosing to abort or continue with the pregnancy (31). A review study conducted by Lie et al also noted the effect of the spouses' attitudes on women's decision in cases of unplanned pregnancy (26). The results obtained by Harvey-Knowles also showed that women paid particular attention to the messages and views expressed by key family members and friends regarding pregnancy, and convincing messages from relatives about unplanned pregnancy affected their decision to abort or continue with the pregnancy (32).

In the present study, information support and advices and instrumental support were factors affecting and predicting the decision to abort; for example, the information support of the medical team in dealing with women opting for abortion could increase the women's information about abortion methods and strengthen their motivation for abortion. Shahbazi et al obtained the same results and reported that consultation with friends and relatives and using their experiences and information about abortion and access to abortion medications affected the decision to abort (24).

In a study conducted by Gipson and Hindin, despite feeling uncomfortable and having a heavy conscience regarding abortion, some couples opted for abortion due to their perceived risks of pregnancy (33). The present findings confirmed the significant effect of perceived moderating beliefs and values on the decision to continue with the pregnancy, which disagrees with the cited study, but concurs with the results of other studies in which women or couples had decided to continue with their pregnancy due to their heavy conscience around the matter of abortion $(10,34)$.

Other factors affecting the decision to abort (as demonstrated in previous studies) included the number of children or completing the household size and the mother's education $(24,25)$, and fetal gender $(21,27)$, which agrees with the present findings. In line with the present study, another study also found gestational age to be an influential factor in the decision to continue with a pregnancy, and an increased gestational age was more associated with the decision to continue with the pregnancy, and that the fetus having a heartbeat in the ultrasound was a factor that prevented women from going on with the abortion (33).

\section{Conclusions}

The results of our study demonstrated that the factors that affected the women's decision on termination of their unplanned pregnancies were complex and interrelated, 
as found in previous studies. Different reasons raised by women with individual particular characteristics were assessed and found that women choose to abort and terminate their unplanned pregnancies due to reasons related to their circumstances, including their perceived threats, supports, believes, any factor related to their socioeconomic status, age, health, parity and so on.

Given the prevalence of unplanned pregnancies and the fact that many women tend to face the challenge of deciding about the outcome of their pregnancy during their reproductive period, and taking into account the high probability of unsafe abortions and the increased mortality or harmful complications of this procedure for young women, the present study promotes the knowledge about the factors affecting and predicting women's decision in the face of an unplanned pregnancy and thus helps policymakers, counselors, and health care providers understand the context in which the decision to abort is made and seek to eliminate this context by increasing life skills and decision-making and problem-solving skills in women by establishing counseling or support centers and adopting appropriate policies. The present study provides a comprehensive viewpoint about predictors of decision making about unplanned pregnancy because of applying a reliable and special instrument, which is a new scale designed as a psychometric tool to assess the factors affecting women's decision about an unplanned pregnancy.

The present findings demonstrate the need for supporting these women through special supportive policies and career and academic provisions to reduce their social deprivations and also through counseling and improved family support. It is essential that policy makers consider women's reasons for choosing abortion, as adopting supportive legislation could have profound effects on life of women facing unplanned pregnancies.

\section{Limitations}

Legal, moral, and ethical issues about unplanned pregnancy and its consequences such as induced abortion placed limitations for researcher, and also affected the quality of the information obtained. Collecting reliable information about perceived threats, supports, and values and believes may be especially difficult, because it requires asking women to articulate the often complex and sensitive process that led to the decision. To overcome the mentioned limitation, in the present study the researcher tried to prepare a reliable and friendly environment for women participated in this research.

\section{Conflict of Interests}

The authors declare no competing financial interests.

\section{Ethical Issues}

The Ethics Committee of Tabriz University of Medical Sciences approved the study protocol (code of ethics:
5/D/21562). All women consented to participate in the study. The participants were informed that their participation was voluntary and their information would be kept confidential.

\section{Financial Support}

Tabriz University of Medical Sciences financed this work.

\section{Acknowledgements}

The authors thank all the women who participated in this study as well as Eunice committee of Tabriz University of Medical Sciences for financing this work under the grant number 5/D/21562.

\section{References}

1. Cameron ST, Glasier A. Identifying women in need of further discussion about the decision to have an abortion and eventual outcome. Contraception. 2013;88(1):128-132. doi:10.1016/j.contraception.2012.10.032

2. Sedgh G, Henshaw S, Singh S, Ahman E, Shah IH. Induced abortion: estimated rates and trends worldwide. Lancet. 2007;370(9595):1338-1345. doi:10.1016/s01406736(07)61575-x

3. Moss DA, Snyder MJ, Lu L. Options for women with unintended pregnancy. Am Fam Physician. 2015;91(8):544549.

4. Picavet C. Zwangerschap en anticonceptie in Nederland [Pregnancy and contraception in the Netherlands]. Tijdschrift voor Seksuologie. 2012;36(2):121-128.

5. Sedgh G, Singh S, Hussain R. Intended and unintended pregnancies worldwide in 2012 and recent trends. Stud Fam Plann. 2014;45(3):301-314. doi:10.1111/j.17284465.2014.00393.x

6. Singh S, Sedgh G, Hussain R, Eilers M. Incidence of unintended pregnancies worldwide in 2012 and trends since 1995. Annual Meeting of the Population Association of America; New Orleans, Louisiana; 2013.

7. Sedgh G, Bearak J, Singh S, Bankole A, et al. Abortion incidence between 1990 and 2014: global, regional, and subregional levels and trends. Lancet. 2016;388(10041):258267. doi:10.1016/S0140-6736(16)30380-4

8. Erfani A. Levels, trends, and determinants of unintended pregnancy in Iran: the role of contraceptive failures. Stud Fam Plann. 2013;44(3):299-317. doi:10.1111/j.17284465.2013.00359.x

9. Motaghi Z, Poorolajal J, Keramat A, Shariati M, Yunesian M, Masoumi SZ. Induced abortion rate in Iran: a metaanalysis. Arch Iran Med. 2013;16(10):594-598. doi:0131610/ aim.009

10. Mortazavi F, Mottaghi Z, Shariati M, Damghanian M. Women's experiences of unwanted pregnancy. J Kermanshah Univ Med Sci. 2012;15.

11. World Health Organization. Preventing unsafe abortion. http://www.who.int/mediacentre/factsheets/fs388/en/. Updated 2 Nov 2016

12. Bankole A, Hussain R, Sedgh G, Rossier C, Kabore I, Guiella G. Unintended pregnancy and induced abortion in Burkina Faso: Causes and consequences. New York: Guttmacher Institute; 2014.

13. Fallahian M, Tavana S. Trends in Techniques of Abortion 
in Iran from 1994 to 2014. J Obstet Gynecol Cancer Res. 2016;1(1):e7539. doi:10.17795/jogcr-7539

14. Erfani A, McQuillan K. Rates of induced abortion in Iran: the roles of contraceptive use and religiosity. Stud Fam Plann. 2008;39(2):111-122.

15. Behjati Ardekani Z, Akhoondi MM, Sadeghi MR, SadriArdekani $\mathrm{H}$. The necessity of a comprehensive study on abortion in Iran. J Reprod Infertil. 2005;24(6):320-299

16. Erfani A. Abortion in Iran: What Do We Know? PSC Discussion Papers Series. 2008;22(1):art1.

17. Santelli JS, Speizer IS, Avery A, Kendall C. An exploration of the dimensions of pregnancy intentions among women choosing to terminate pregnancy or to initiate prenatal care in New Orleans, Louisiana. Am J Public Health. 2006;96(11):2009-2015. doi:10.2105/ajph.2005.064584

18. Karacam Z, Onel K, Gercek E. Effects of unplanned pregnancy on maternal health in Turkey. Midwifery. 2011;27(2):288-293. doi:10.1016/j.midw.2009.07.006

19. Mohammadpoorasl A, Rostami F, Ivanbagha R, Torabi S. Prevalence of unwanted pregnancy and multivariate analysis of its correlates in Tabriz city, 2004. Medical Science Journal of Islamic Azad Univesity Tehran Medical Branch. 2005;15(4):201-206.

20. Yanikkerem E, Ay S, Piro N. Planned and unplanned pregnancy: effects on health practice and depression during pregnancy. J Obstet Gynaecol Res. 2013;39(1):180-187. doi:10.1111/j.1447-0756.2012.01958.x

21. Bankole A, Singh S, Haas T. Reasons why women have induced abortions: evidence from 27 countries. Int Fam Plan Perspect 1998;24(3):117-152.

22. Kirkman $M$, Rowe $H$, Hardiman A, Mallett $S$, Rosenthal D. Reasons women give for abortion: a review of the literature. Arch Womens Ment Health. 2009;12(6):365-378. doi:10.1007/s00737-009-0084-3

23. Nourizadeh R. Development and psychometric testing of instruments to measure decision-making status in unintended pregnant women [thesis]. Tehran: Shahid Beheshti University of Medical Sciences and Health Services; 2015.

24. Shahbazi SH, Fathizadeh N, Taleghani F. Explain the process of illegal abortion: A Qualitative Study. Payesh. 2011;10:183. [Persian].

25. Zamani Alaviche F, Eftekhar Ardebili H, Bashardost N, Marashi T, Naghibi A. The behavior of women confronted with unwanted pregnancies. Journal of School of Public Health and Institute of Public Health Research. 2004;2(2):55-62. [Persian].

26. Lie ML, Robson SC, May CR. Experiences of abortion: a narrative review of qualitative studies. BMC Health Serv Res. 2008;8:150. doi:10.1186/1472-6963-8-150

27. Mohammadi E, Nourizadeh R, Symber M. Reasons to Search Abortion in Unwanted Women: A Qualitative Study. Payesh. 13:413-424. [Persian].

28. Frederico M, Michielsen K, Arnaldo C, Decat P. Factors Influencing Abortion Decision-Making Processes among Young Women. Int J Environ Res Public Health. 2018;15(2). doi:10.3390/ijerph15020329

29. Hoogen SR. Contexts of choice: Personal constructs of motherhood in women's abortion decisions. Miami University; 2010.

30. Wilson EK, McQuiston C. Motivations for Pregnancy Planning Among Mexican Immigrant Women in North Carolina. Matern Child Health J. 2006;10(3):311-320. doi:10.1007/s10995-005-0055-x

31. Bayrami R, Taghipour A, Ebrahimipour H. Experience of Unplanned Pregnancy in Women Attending to Health Centers of Mashhad, Iran: A Phenomenological Study. Iranian Journal of Obstetrics, Gynecology and Infertility. 2014;16(87):15-23.

32. Harvey-Knowles JA. An Examination of Women's Decision-Making Processes During Unplanned Pregnancy. Qualitative Research Reports in Communication. 2012;13:80-87.

33. Gipson JD, Hindin MJ. "Having another child would be a life or death situation for her": understanding pregnancy termination among couples in rural Bangladesh. Am J Public Health. 2008;98(10):1827-1832. doi:10.2105/ ajph.2007.129262

34. Nourizadeh R, Mohammadi E, Simbar M. Womens coping with an unplanned pregnancy. Payesh. 2015;14:73-84.

(C) 2018 The Author (s); This is an open-access article distributed under the terms of the Creative Commons Attribution License (http://creativecommons.org/licenses/by/4.0), which permits unrestricted use, distribution, and reproduction in any medium, provided the original work is properly cited. 